\title{
Conceptual Models as Tools for Communication Across Disciplines
}

\author{
$\underline{\text { Marieke Heemskerk }}{ }^{1}, \underline{\text { Karen Wilson }}{ }^{2}$, and Mitchell Pavao-Zuckerman ${ }^{3}$
}

\begin{abstract}
To better understand and manage complex social-ecological systems, social scientists and ecologists must collaborate. However, issues related to language and research approaches can make it hard for researchers in different fields to work together. This paper suggests that researchers can improve interdisciplinary science through the use of conceptual models as a communication tool. The authors share lessons from a workshop in which interdisciplinary teams of young scientists developed conceptual models of social-ecological systems using data sets and metadata from Long-Term Ecological Research sites across the United States. Both the process of model building and the models that were created are discussed. The exercise revealed that the presence of social scientists in a group influenced the place and role of people in the models. This finding suggests that the participation of both ecologists and social scientists in the early stages of project development may produce better questions and more accurate models of interactions between humans and ecosystems. Although the participants agreed that a better understanding of human intentions and behavior would advance ecosystem science, they felt that interdisciplinary research might gain more by training strong disciplinarians than by merging ecology and social sciences into a new field. It is concluded that conceptual models can provide an inspiring point of departure and a guiding principle for interdisciplinary group discussions. Jointly developing a model not only helped the participants to formulate questions, clarify system boundaries, and identify gaps in existing data, but also revealed the thoughts and assumptions of fellow scientists. Although the use of conceptual models will not serve all purposes, the process of model building can help scientists, policy makers, and resource managers discuss applied problems and theory among themselves and with those in other areas.
\end{abstract}

\section{INTRODUCTION}

More effective ecosystem management requires policy makers to understand and mediate both the human and the biological factors that drive ecological change, as well as the interactions between them (Lee 1993, Gunderson et al. 1995). To reach a holistic understanding of human-altered ecosystems, ecologists and social scientists must collaborate (Turner and Carpenter 1999, Bradshaw and Bekoff 2001). However, because of a lack of common goals, theories, and concepts, working with scientists from other fields is not an easy endeavor. In this report, we (1) propose conceptual modeling as a tool to improve communication across disciplines and (2) share what we learned from a recent workshop in which interdisciplinary teams developed models of existing social-ecological systems.

Although interdisciplinary research can merge people and ideas from any fields, in this paper we use the term exclusively to describe collaboration between ecologists and social scientists. Further, we propose that interdisciplinary research will benefit from the equal participation of both disciplines in all aspects of research, from question design and project implementation to data analysis and interpretation. Such an approach differs from research that is designed by scientists from one field who then ask experts from another field to solve a specific problem within the larger project.

Despite increasing interest in and support for interdisciplinary endeavors at universities and funding agencies, few guidelines exist on how to do interdisciplinary research (Pickett et al. 1999). According to Turner and Carpenter (1999), there is no "cookbook" of procedures for tackling interdisciplinary ecosystem science. Scientists who have bridged disciplinary boundaries emphasize that such teamwork requires trust, understanding, communication skills, and, perhaps the most 
important, friendship (Daily and Erhrlich 1999, Naiman 1999, Scoones 1999). Unfortunately, few researchers offer hands-on examples. Although good interdisciplinary work may not depend on faithful adherence to cookbooks, we do believe that it advances when scientists share experiences, tools, and recipes. The purpose of this paper is to do just that.

As part of the 2001 Ecological Society of America annual meeting in Madison, Wisconsin, we organized a one-day workshop in which we asked interdisciplinary teams to build conceptual models for existing social-ecological systems. In the following pages we describe our motivations and objectives, the workshop setting, and the modeling exercise. We share what we learned from both the model building process and the models themselves, and conclude with some of the benefits and pitfalls involved in using conceptual models as a tool in interdisciplinary work.

\section{MODELING SOCIAL-ECOLOGICAL SYSTEMS}

A model is an abstraction or simplification of reality. Scientists often use models to explore systems and processes they cannot directly manipulate (Jackson et al. 2000). Models can be more or less quantitative, deterministic, abstract, and empirical. They help define questions and concepts more precisely, generate hypotheses, assist in testing these hypotheses, and generate predictions (Turner et al. 2001). Model building consists of determining system parts, choosing the relationships of interest between these parts, specifying the mechanisms by which the parts interact, identifying missing information, and exploring the behavior of the model. The model building process can be as enlightening as the model itself, because it reveals what we know and what we don't know about the connections and causalities in the systems under study (Levins 1966, Jackson et al. 2000, Taylor 2000). Thus modeling can both suggest what might be fruitful paths of study and help pursue those paths.

We used conceptual rather than computer simulation or empirical models, because conceptual models require few resources and little prior modeling experience, and are critical in defining research questions (Pavao-Zuckerman 2000). Conceptual or qualitative models are typically drawn as diagrams with boxes and arrows that show the main elements and flows of material, information, and causation that define a system. Generating a visual model with colleagues who may not be familiar with one's methods and theoretical approaches can be enervating. It requires model builders to explicitly explain to their colleagues why they believe that certain elements are important, what assumptions are automatically made by researchers in their particular field, and how key concepts are defined (Taylor 2000).

At the workshop, five groups of four to six participants developed models of existing social-ecological systems using flip charts, construction paper, and markers. Each group received a sheet with symbols in the style of H. T. Odum (Appendix 1) that the participants could use, modify, or ignore. In other words, we did not ask people to use the symbols "correctly," but rather to use them as a guide or inspiration to develop a conceptual model. We choose Odum's symbols because they are familiar to many ecologists and social scientists and easily understood by neophytes. The groups had $2 \mathrm{~h} 30 \mathrm{~min}$ to design their models before presenting them to the workshop. This time constraint probably helped keep the models parsimonious.

\section{WORKSHOP SETTING AND GOALS}

The workshop organizers elicited the participation of graduate students with backgrounds in the social sciences and ecology who were affiliated with one of the nationwide Integrative Graduate Education Research and Training (IGERT) programs and/or Long-Term Ecological Research (LTER) sites. Twenty-six participants and two facilitators came from 11 universities throughout the United States. They represented four IGERT programs and six LTER sites (Appendix 2).

Most participants were graduate students, but a few professionals and postdoctoral researchers as well as an undergraduate student also attended. Although we agree with Daily and Ehrlich (1999) that the commitment of senior people is crucial to the institutionalization of interdisciplinary research, we had several reasons for soliciting the participation of young scientists. First, we believe that it is important to foster interdisciplinary work early in scientific careers. Starting early gives a student more time to work with and learn from colleagues in other fields. Second, even though the National Science Foundation encourages interdisciplinary work at LTER sites, ecology graduate students felt that there have been too few opportunities to collaborate with social scientists. Third, researchers who have not yet defined 
themselves academically may be in an advantageous position to engage in interdisciplinary endeavors, because they tend to be more open to ideas that do not fit the dogma of their individual fields. A disadvantage of junior scholars is that they may not have the credibility to represent the theoretical and methodological position of their fields in discussions with others (Golde and Gallagher 1999).

Fig. 1. Workshop participants on axes. The horizontal axis ranges from qualitative (right) to quantitative (left); the vertical axis, from human (top) to natural (bottom) systems.

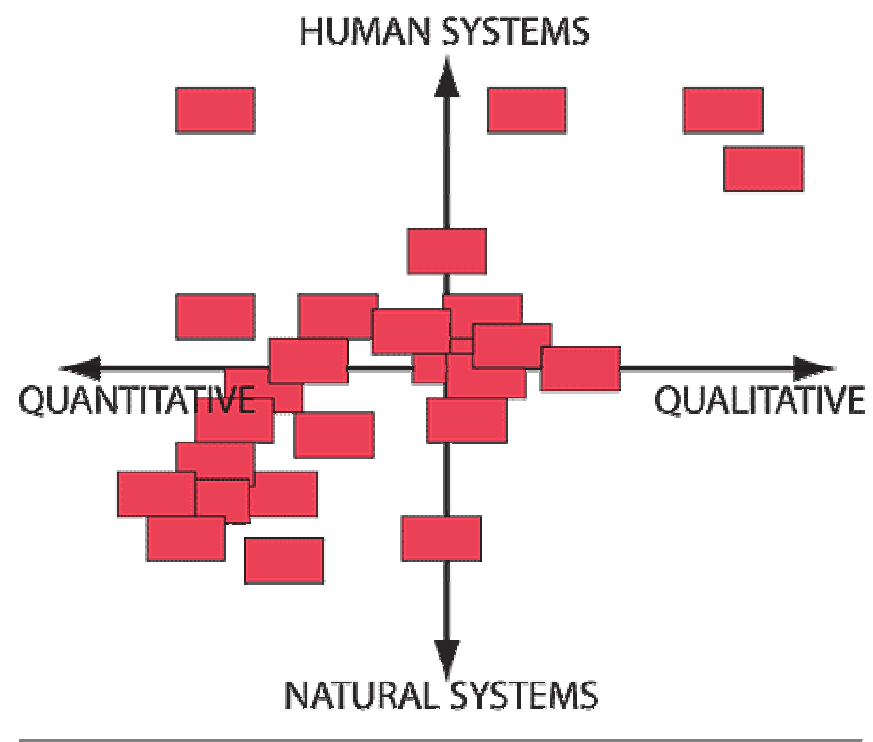

Throughout the workshop we emphasized informality and collegiality. We used common facilitation techniques to encourage open and frank discussion, included time for informal socializing, and provided food and snacks throughout the day. We began the morning with introductions, the presentation of the workshop goals, and an ice-breaking exercise. In this exercise we asked each participant to interview a colleague and use a sticky note to plot this person on a two-dimensional graph. The axes on the graphs represented the following gradients: (1) quantitative vs. qualitative research, (2) natural vs. social scientist, (3) studying human vs. ecological systems, and (4) theoretical vs. applied research (Fig. 1). This activity introduced people to one another, revealed the diversity among participants, and helped facilitators divide participants into heterogeneous groups for the modeling exercise.

The axes exercise revealed that most researchers did not identify themselves as pure social scientists or ecologists, but rather placed themselves somewhere on a continuum between these extremes (Fig. 2). In addition, participants noted that ecologists placed more emphasis on quantifying observations than did social scientists. The urge to put numbers on observations seemed to stem from two factors. First, quantification facilitates generalization and comparison of data. Second, ecologists often view qualitative data as less objective and therefore less scientific. Discussion revealed that a preference for either qualitative or quantitative methods not only divides disciplines, but can also be a source of tension between scientists within any scientific field.

Fig. 2. Workshop participants on axes. The horizontal axis presents a range from social (left) to natural scientists (right), and the vertical axis extends from applied (top) to theoretical (bottom) research.

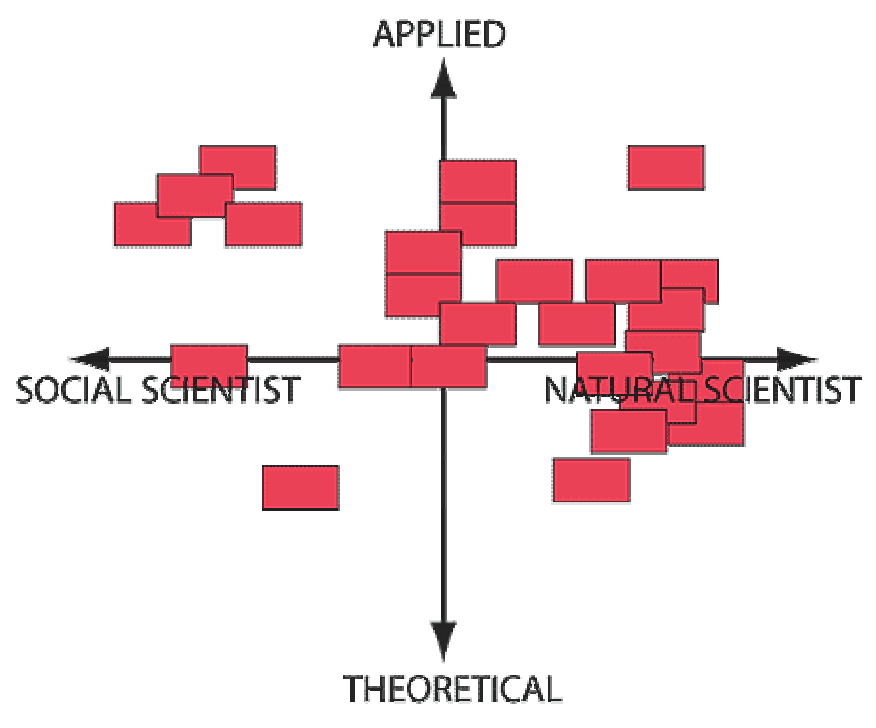

Representatives briefly presented longitudinal social and ecological data from six LTER sites, including the Andrews Experimental Forest in Oregon, the Central Arizona Phoenix LTER, the Florida Coastal Everglades, Kellogg Biological Station in Michigan, the Luquillo Experimental Forest in Puerto Rico, and one international site in Israel. Data sets represented either personal research projects or were part of the LTER network. More information about each project is available from their Web sites, and most data are publicly available on line (http://www.lternet.edu).

We chose to use LTER data for several reasons. First, the LTER network is encouraging more interdisciplinary research. It is our hope that informal 
yet science-based encounters with people from other fields will inspire young LTER scientists to actively seek out such collaborations in their future work. Second, LTER data allow researchers to detect how social and ecological elements codevelop over large areas and long time spans. This feature makes LTER data well suited for modeling. Third, scientists from different fields are more likely to find common ground when focusing on real-world problems than in discussions about abstractions and theory. Finally, the data were collected in diverse social-ecological systems including forests, deserts, north temperate lakes, agricultural systems, and urban landscapes. Comparing and contrasting different sites provided an opportunity to detect commonalities in the processes that drive social-ecological systems.

Each group of participants was instructed to develop a conceptual model for one of the LTER systems presented, focusing on one main research question or problem. We did not ask the groups to make a model that reflected the research objectives of the LTER program, but one that included variables and variable interactions that were likely to indirectly or directly affect the LTER sites. Some groups found it difficult to develop a suitable research question from the limited data available in such a short time frame. In addition to a central question, model builders had to define (1) system boundaries, (2) driving forces, (3) directions and strengths of flows and interactions, and (4) scale and hierarchy. We asked each group to assign one person to keep track of the modeling process and one person to report on the product. A discussion of the process and the product followed the model presentations.

\section{LESSONS LEARNED}

From our discussion of the modeling process we wanted to learn how working in interdisciplinary groups differed from working with people in one's own field, what communication problems arose, and what helped to overcome or avoid these problems. Two main themes emerged from this discussion: the need to define the word "interdisciplinary" and the issue of a common language. In terms of product, we discussed the place of human and ecological components in the model to determine whether they were central or peripheral to the system. In addition, participants questioned whether research, management, and ecosystem processes and functions occurred at comparable scales.
The lessons learned are generally expressed from the point of view of the workshop facilitators. Unless explicitly stated, this point of view does not necessarily reflect the opinions of all the workshop participants. Figs. 3-5 document the process of model building, and Figs. 6-11 show the final models.

Fig. 3. Starting on paper. A workshop participant lists the main elements of the Luquillo Experimental Forest model and draws connections between them.

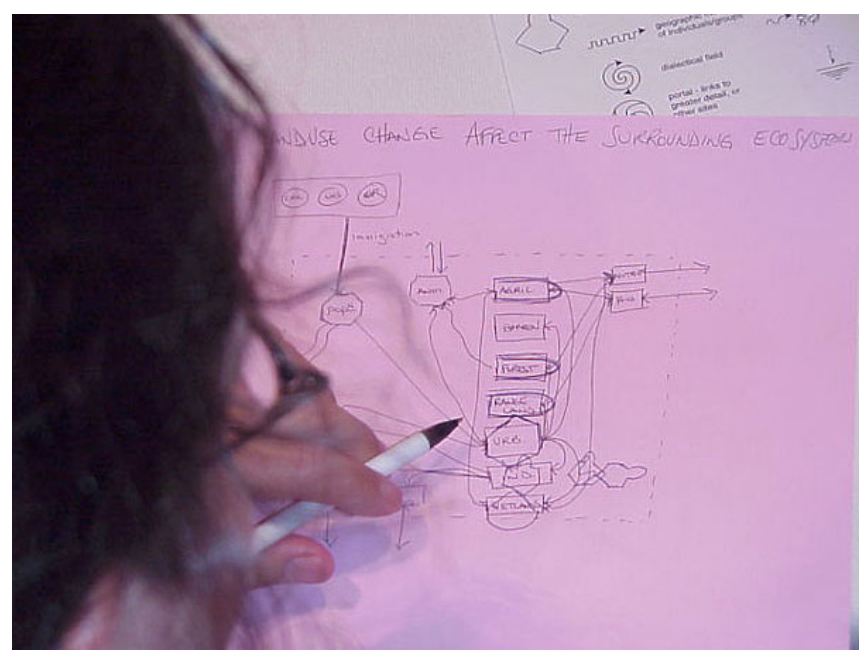

\section{PROCESS}

\section{The meaning of "interdisciplinary"}

The workshop participants agreed that the study of human society deserves a more central place in ecosystem science. Indeed, people have altered virtually every ecological system, and biological language is peppered with cultural constructs such as "endangered plant" and "nature." At the same time, even though ecological and social systems are intrinsically linked, the participants questioned the benefit of merging ecological and social sciences into a new discipline, such as the union of biology and chemistry that produced biochemistry. The consensus was that high-quality interdisciplinary science requires skilled disciplinarians who are curious about theories and methods from other fields. It can be useful to explain to an ecologist why, when, and how one would use a specific interview instrument such as a scale to measure people's attitudes. It is also valuable to obtain first-hand experience in collecting field data from another discipline. However, asking an expert in ecology to routinely collect data on attitudes is probably an ineffective use of human resources. 


\section{Common language}

In our experience and that of others, collaboration is likely to fail when scientists communicate poorly, have unrealistic expectations of one another, and internalize prejudices about alien academic fields (Turner and Carpenter 1999). Communication problems arise from the use of jargon and terms that mean different things to different people. An anthropologist and a biologist will define "community" and "scale" differently, and they probably disagree on how to study them. Further, scientists from under-represented fields in interdisciplinary teams often feel that their knowledge is simplified and misrepresented. For example, we have heard social scientists complain that they are invited to participate in interdisciplinary teams merely to "... find out what people think ...," which may not be their area of expertise.

Fig. 4. A workshop participant organizes the components of the Florida Coastal Everglades model. Most of the symbols have been created, and some connections have been drawn between them.

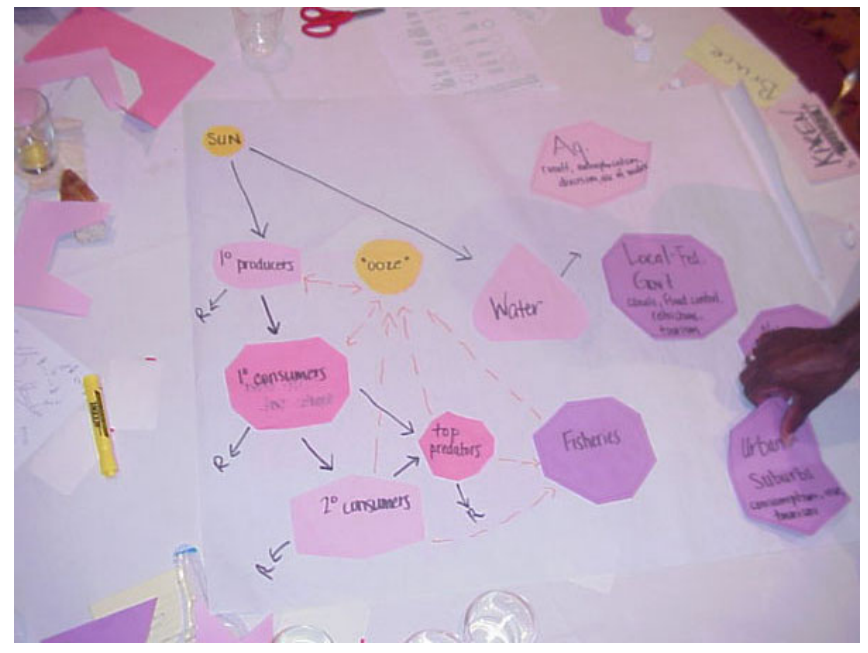

Participants found that the process of constructing a model together and talking about their underlying assumptions reduced confusion and ideological confrontations both within and across disciplines (see also Taylor 2000). For example, some workshop groups lumped values, ideas, opinions, and beliefs into one box representing the human mental world (Figs. 8 and 11). During the discussion session, a sociologist expressed dissatisfaction with this picture because, in her field, the difference between values and opinions is crucial. More information can change a person's opinion, but values typically are more deep-rooted and harder to change. Hence, resource managers who hope to change human behavior need to know whether observed behavior is caused by values or opinions. Depending on the model goals, it may or may not be useful to distinguish between these concepts.

Fig. 5. Piecing together a conceptual model of the Kellog Biological Station. After formulating and creating model components, group participants organized the symbols in space and drew connections between them on flip charts. All the conceptual models were placed on the wall for presentation.

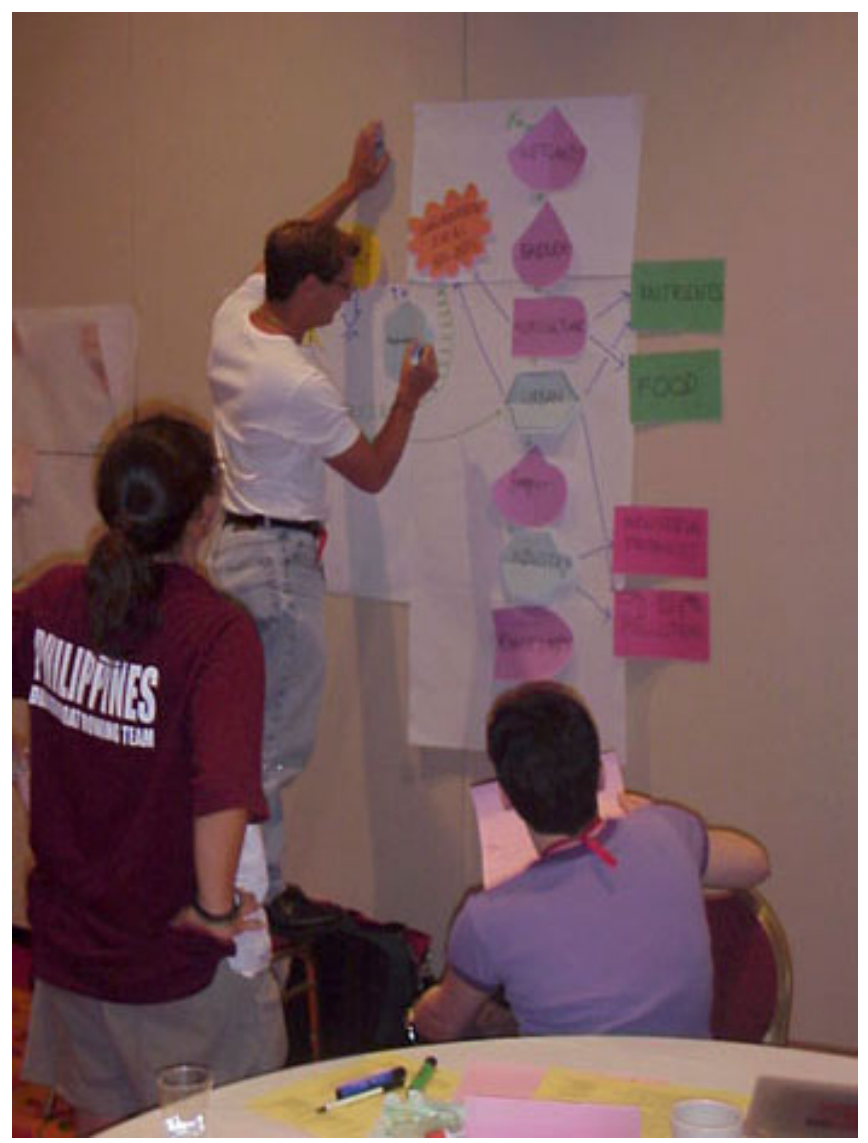

\section{PRODUCT}

\section{The place of people}

The model builders at this workshop situated people as the central drivers of environmental change in all five models. At the same time, we noted that the participants found the human component difficult to represent (see also Redman 1999). The final models 
varied in the extent to which they distinguished between types of people (e.g., fishers vs. farmers), types of behavior (e.g., political or economic), and mental processes (e.g., values and attitudes). For example, the Kellogg Biological Station model limited anthropogenic processes mostly to flows of information, ideas, and beliefs (Fig. 8). In contrast, the group modeling the Andrews Experimental Forest incorporated a more complex human world with different stakeholders that included governmental and nongovernmental institutions, scientists, the media, the public, and others (Fig. 10). In this model, all the feedback loops cycled through a human/harvesting practices diagram. Generally, the models were less explicit about how nature influenced people, although the Luquillo Experimental Forest model does show that the state of the coral reefs determines the fate of the tourist industry (Fig. 8).

Fig. 6. Florida coastal everglades Long-Term Ecological Research (LTER) site. The Florida LTER analyzes how regional forces (e.g., climate change, changing freshwater inflow) control population and ecosystem level dynamics in wetlanddominated coastal landscapes. The data presented showed long-term changes in both management policies and the diversity and abundance of bird species. Using a food-web approach, the group developed a model that depicts the use of, and competition for, water among different human interest groups, including agriculture, urban environments, government, and recreation and fisheries. These groups exchange information and resources. Purple symbols represent social institutions and mental variables such as beliefs. The pink symbols on the left represent ecological processes and elements. Human use of water affects the aquatic ecosystem and changes the aquatic biological communities that generate ecosystem services and products. All these forces are leading through ooze, a bacterial recycling mechanism.

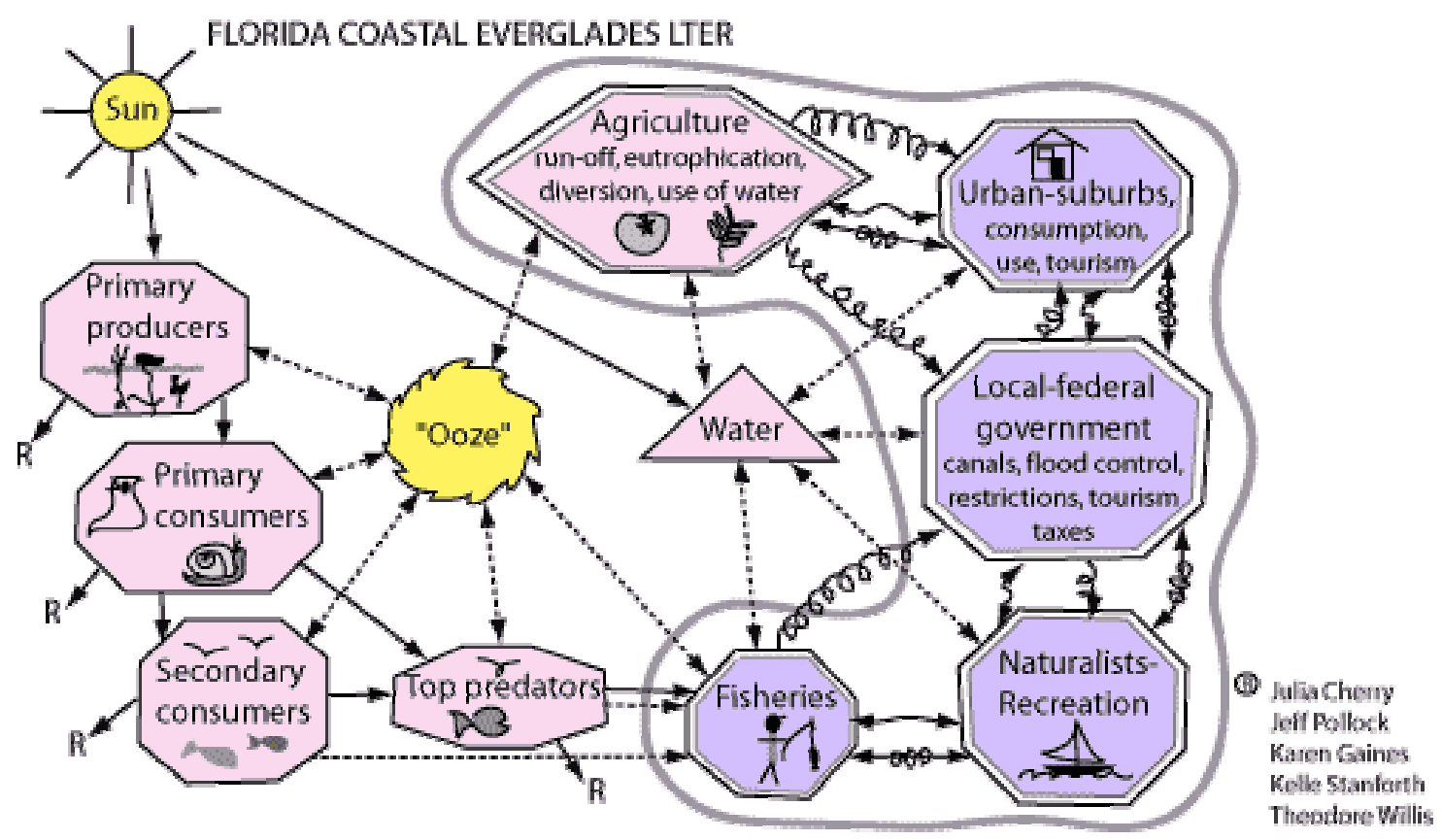

The participants identified two factors that made it harder to model the human element. First, because the workshop was part of an ecological society meeting, ecologists outnumbered social scientists. Most participants were ecologists with limited experience modeling nonecological interactions. A more balanced pool of participants would decrease the pressure on the social scientists in a group to speak for all the social sciences, reveal the diversity within the social sciences, and possibly create models that include more anthropogenic detail. Second, ideas, beliefs, and values are sticky abstract issues. It is difficult to measure these concepts and relate them to abstractions at larger scales such as institutions and regulations. To see social scientists add detail to the human element can be eye-opening, but does not necessarily clarify what a box labeled "values" really means. Further, it is possible that ecological interactions only seem easier to model because fish and daphnia do not complain when their interests and behavior are misrepresented. 
Fig. 7. Israel International Long-Term Ecological Research site. The Israel research project analyzes how human decisions and activities affect the distribution of resources (soil, water, and nutrients) in a rangeland ecosystem. The model depicts the social and ecological factors that affect grazing conditions in semi-arid shrub lands in South Israel. Key variables include nitrogen, sheep, and grazing management by Bedouins. Grazing affects productivity and the diversity of shrub patches and intershrub patches. The risks of desertification are increasing as the Bedouin semi-nomadic culture becomes increasingly sedentary and livestock rearing becomes less popular.

\section{How do social \& ecological factors affect grazing conditions in S. Israel?}
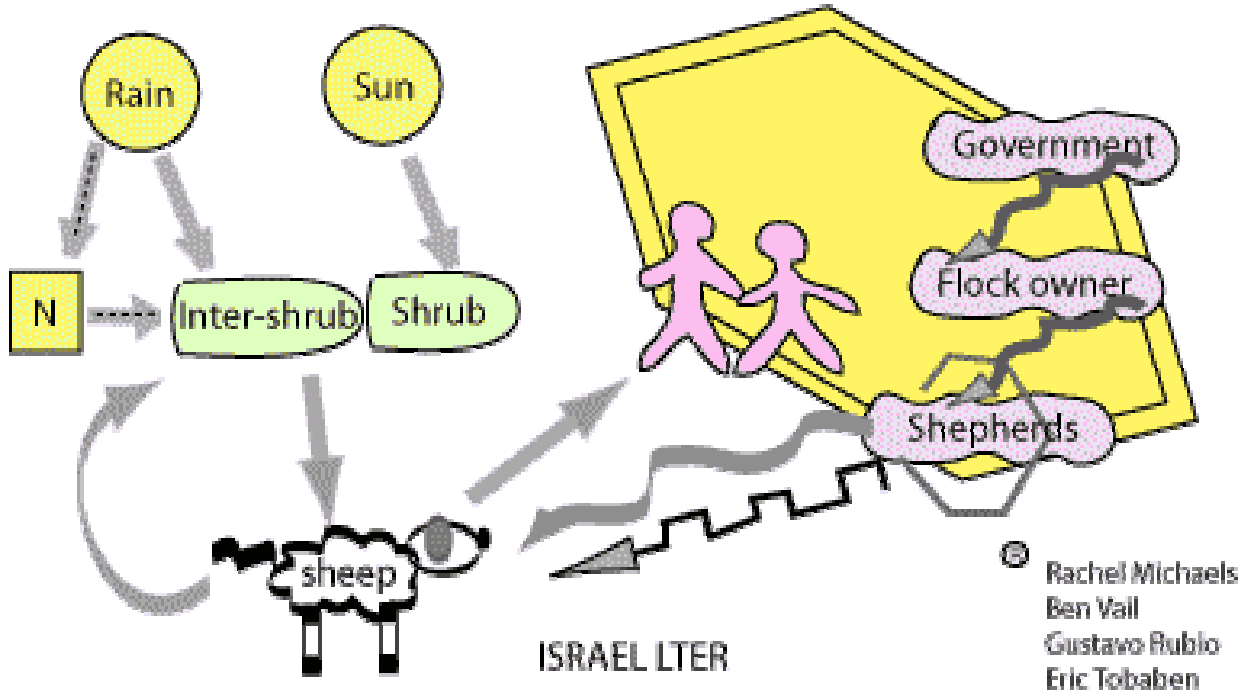

Fig. 8. The Kellogg Biological Station Long-Term Ecological Research (LTER) site. This LTER program in southwest Michigan studies the ecological interactions underlying the productivity and environmental impact of production-level cropping systems. Vegetation in this area is characterized by forest with large areas of croplands and some wetland. The main question driving this model is how land use has changed over time, and how these changes feed back into linked socialecological systems. The data sets presented suggested that urban expansion from three population centers-Chicago, Lansing, and Grand Rapids-is changing the relative scale and impact of other types of land use, in particular, agriculture. Information, ideas, and beliefs are grouped in the gold cloud and influence resource use. The model suggests that population growth will create extra demands on water resources.

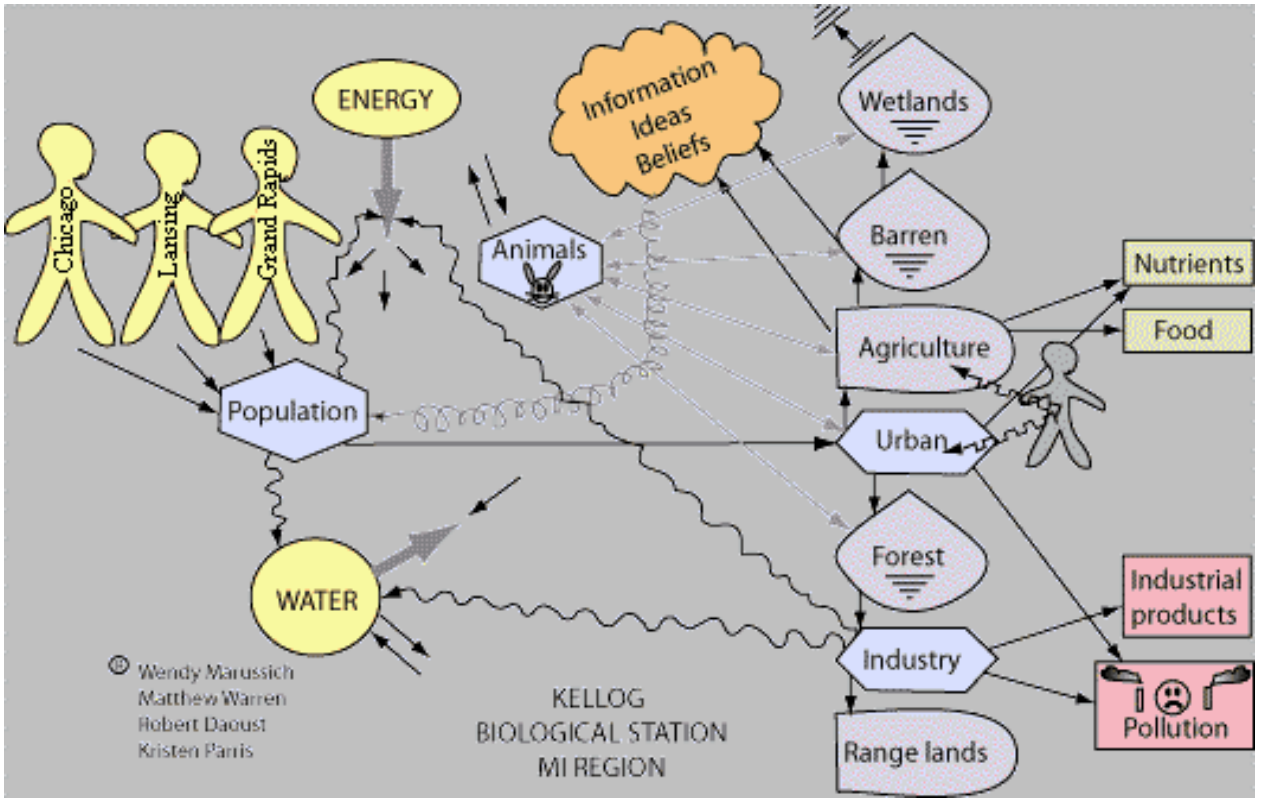


Fig. 9. The Luquillo Experimental Forest Long-Term Ecological Research site. The Luquillo project in Puerto Rico analyzes ecosystem responses to increased tourism. Future development might damage coastal forests and wetlands, which include habitat for endangered species, important nesting beaches for leatherback sea turtles, and coral reef communities. The model's main internal drivers are economic, ethical, political, social, and ecological sustainability. External drivers include sun, rain, natural forest, and a world pool of tourists (purple circle). The model indicates that different stakeholder groups, including local residents, policy makers, tourists, the media, and private industry, will shape the pace and extent of ecological impacts by tourism-related development. The model presents a feedback loop between tourism development and the state of natural resources, because the quality of coral reefs and fish populations determines the number and kind of tourists who will visit the area.

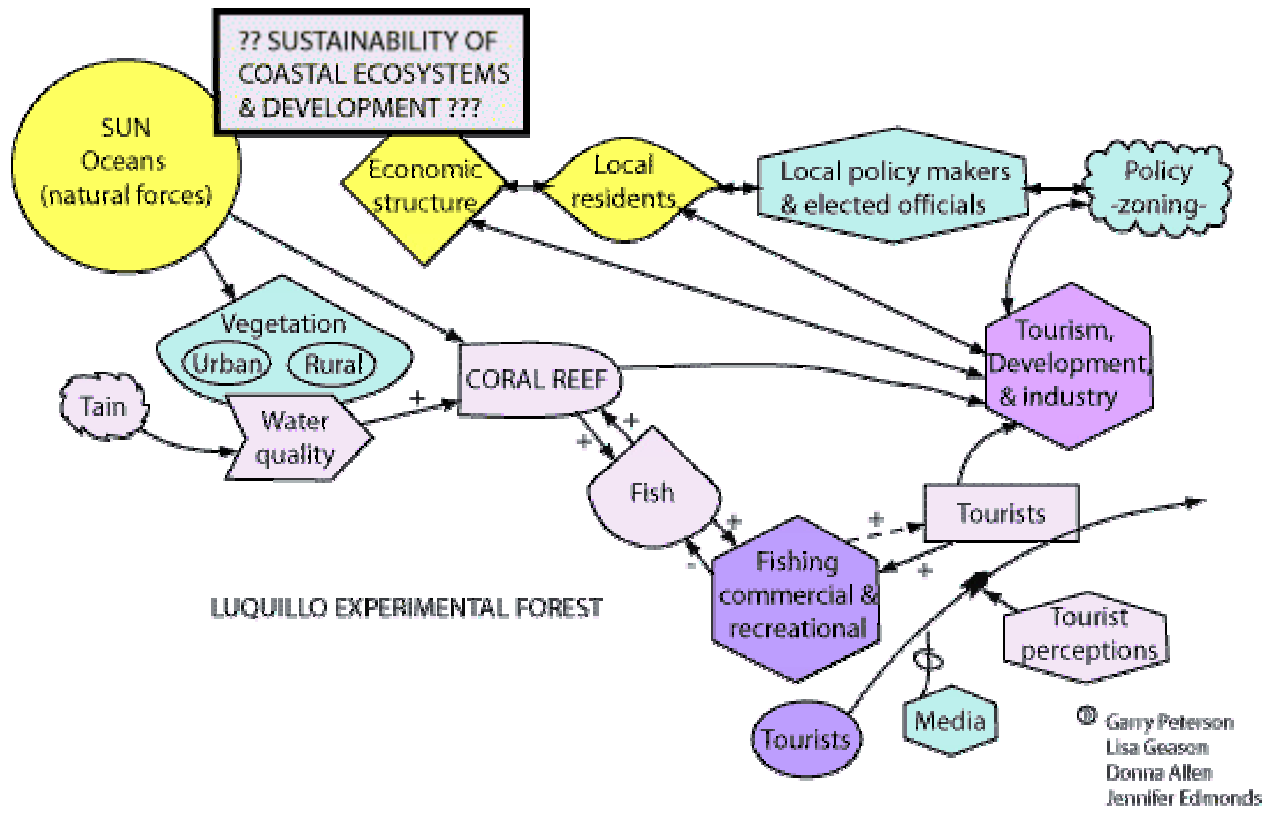

Fig. 10. The Andrews Experimental Forest Long-Term Ecological Research (LTER) site. Scientists at this LTER site in the Cascade Mountain Range, Oregon, study successional changes in ecosystems, focusing on forest-stream interactions. Historically, the area has been economically dependent on the production of timber, which has been extracted through different management regimes. An important question driving the model is how public perception of research at the site influences local resource use and management. Harvesting practices and data collection are central in this model. Information filters influence the receipt and interpretation of data by different stakeholders who make harvest decisions. Harvest decisions in turn affect ecological resources and flows (yellow shapes). The model conveys that, by collecting and publishing data, scientists can influence future regional development and ecosystem management. The USFS is the U.S. Forest Service.

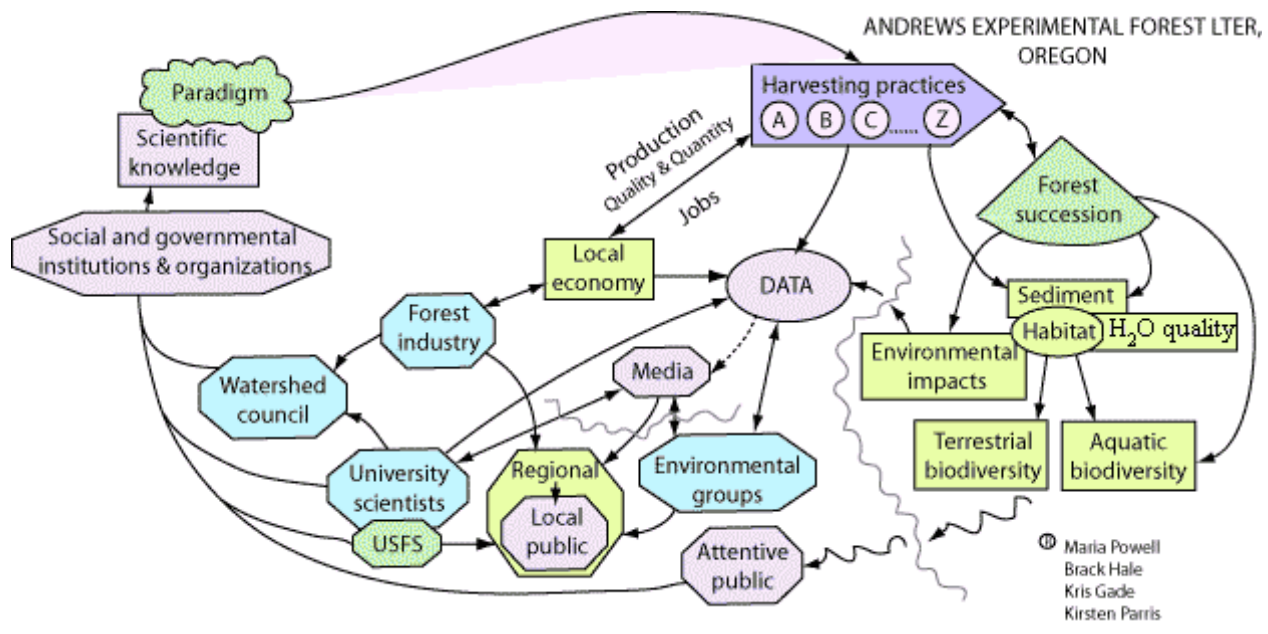


Fig. 11. The Central Arizona Phoenix Long-Term Ecological Research site. This project studies the interactions between ecological and socioeconomic systems in an urban desert environment. One of its goals has been to document the history of changes in land use and its role in shaping the urban, recreational, agricultural, and desert landscapes of today. The modeling group did not define one overlying model question, but did examine the resiliency of native plants to urban development and the introduction of non-native species. The model shows how human and biological processes shape the interactions between introduced and native species in urban environment. The concentric circles at the edges of the model represent urban expansion. Values and beliefs shape people's conceptions of what their residential and natural surroundings should look like, and hence may strongly influence future plant composition in this area. It is suggested that water is a key limiting factor in the future social-ecological urban environment around Phoenix.

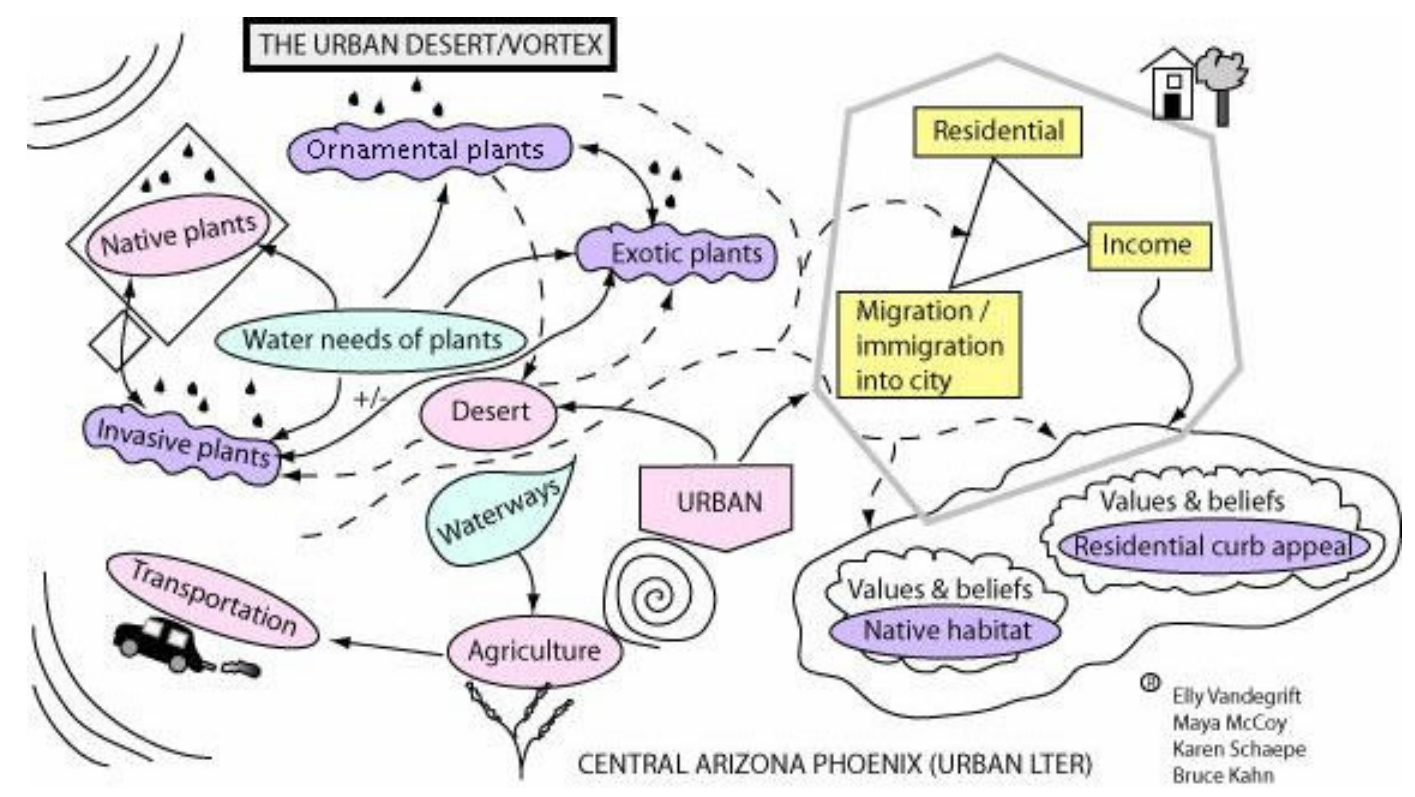

\section{Scale}

The conceptual models covered a range of different scales and presented some of the interactions between them. For example, the Florida model (Fig. 6) conveys that elements ranging from primary producers at the smallest scale to federal governments at a regional level influence the status of aquatic ecosystems. The workshop participants noted that the spatial and temporal scales at which ecosystems function and ecological problems manifest themselves do not necessarily overlap with the scale at which management and research occur. We believe that models can reveal these discrepancies and indicate the scale at which management decisions may be most effective. In addition, models may suggest how processes at different scales interact and what data should be collected at different scales to address these interactions.

\section{CONCLUSIONS: BENEFITS AND PITFALLS OF INTERDISCIPLINARY MODELING}

Although scientists and resource managers are becoming increasingly aware that today's environmental problems require interdisciplinary solutions, we rarely discuss the types of tools that can improve interdisciplinary science in practice. Our experience suggests that the development of conceptual models can guide and facilitate discussion about social-ecological systems among ecologists and social scientists. The workshop participants enjoyed the exercise and learned from one another. Discussions between collaborators may become more tense when there is more at stake, such as a research proposal, an actual case study, or a research project. Nevertheless, we feel that these models were excellent tools for initiating discussions, revealing hidden and unacknowledged assumptions, and identifying areas in which scientists from different fields agreed or disagreed. 
Although good will and adequate tools are necessary, they are not the sole ingredients in interdisciplinary recipes. Young scientists can only be constructive partners in interdisciplinary research if their institutions allow them to. For this reason, it is disheartening to observe that university infrastructures remain hostile to collaborations across departments and colleges. Students have found that papers coauthored with someone in another field may not be accepted as part of the dissertation and are harder to publish. The physical separation of workplaces further discourages interaction. Universities that are serious about fostering interdisciplinary science should evaluate and eliminate bureaucratic and institutional obstacles to innovative approaches to science.

Conceptual models will not serve each and everyone's purpose. Policy makers who want to forecast may prefer quantitative models. Anthropologists may want to know whether material or ideological forces are driving behavior, and resource managers may seek educational or legal measures that could change this behavior. Simple box-and-arrow models typically lack the detail and empirical basis to answer these questions, but they may inform research that does. Indeed, conceptual models can be useful to scientists, policy makers, and resource managers, among themselves or in communication with one another. Models not only help formulate questions, clarify system boundaries, and identify gaps in existing data, but also reveal the thoughts and assumptions of fellow scientists.

For interdisciplinary science to develop, we believe that it is important for ecologists and social scientists to work together from the earliest stages of question formulation and research design. Models can guide this process. We also believe that the ability to work with people from other disciplines is a crucial skill for young scientists who are striving to improve the health of social-ecological systems for future generations. Practice and experience can improve tools and skills. It is our hope that our example will inspire collaboration among social scientists and ecologists who aim to understand the anthropogenic and biological forces that are driving ecological change.

Responses to this article can be read online at: http://www.consecol.org/vol7/iss3/art8/responses/index.html

\section{Acknowledgments:}

We would like to thank all workshop participants for their enthusiast and insightful contributions. We also greatly appreciate the financial sponsorship of the workshop by the University of Wisconsin IGERT program.

\section{APPENDIX 1. Symbols Used in the Modeling Exercise}

These symbols were based on the conventions established by H. T. Odum (1983) and in Pavao-Zuckerman (2000) and Stepp (1999). 


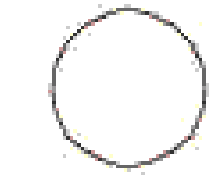
outside system

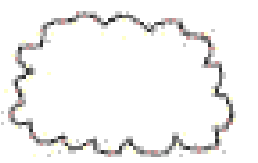

information source beliets, etc.

energy producer primarily plants

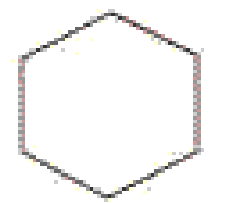

consumer - transforms energy or information

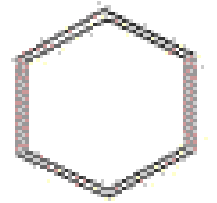

organized group of consumers, or institutions

energy pattmvay/low<smiles>CCC(C)CC</smiles>

Лллル $>$ geographic movement of individuals/groups

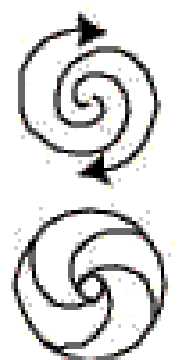

dialectical field

portal- - links to greater detai, or other sites energy source,
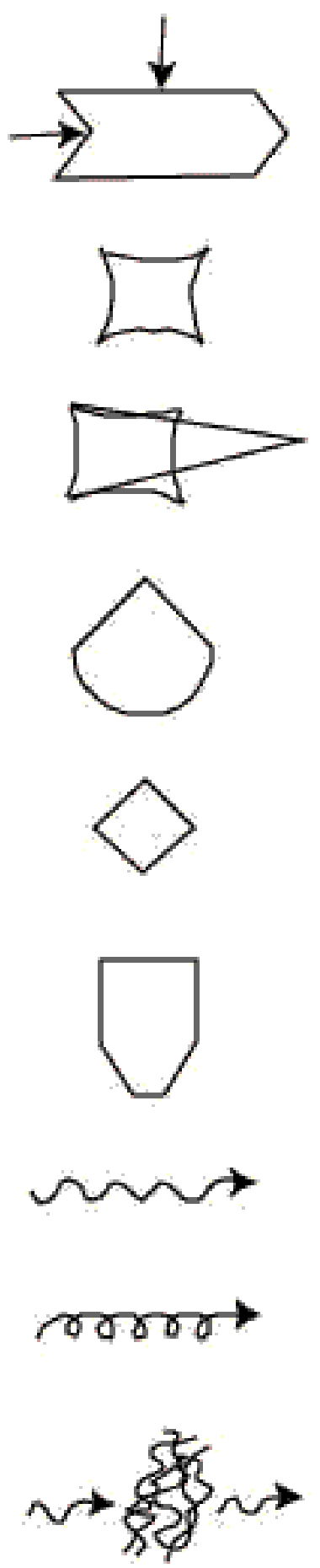

interaction - two paths connected and producing new outflow; workgate

switch - selects possible results

change or transformation - of energy or information

storage - stores matter, energy or information to balance flows

transaction exchange of one thing for another

comparator compares incoming energy, matter, or information before creating an output

information pattmwaylitow

propaganda to promote something

information fieldifilter' screen/editor

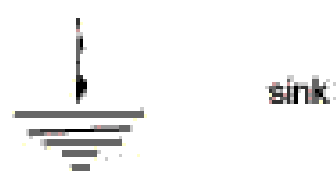




\section{APPENDIX 2. List of Workshop Participants}

The names of the workshop facilitators have not been included to protect their anonymity.

\begin{tabular}{|c|c|}
\hline Workshop participants & Affiliation \\
\hline Donna Allen & University of North Carolina, Department of Conservation Biology \\
\hline Kirsten Blann & University of Michigan, Department of Conservation Ecology \\
\hline Julia A. Cherry & University of Alabama, Department of Biological Sciences \\
\hline Robert Daoust & University of South Carolina, Department of Biological Sciences \\
\hline Jennifer Edmonds & Arizona State University, Department of Biology \\
\hline Kris Gade & Arizona State University, Department of Biology \\
\hline Karen Gaines & University of New Mexico, Department of Biology \\
\hline Lisa Geason & Michigan State University, Department of Sociology \\
\hline Rick Haeuber & Political Scientist, Environmental Protection Agency, Washington DC \\
\hline Brack Hale & University of Wisconsin, Madison, Institute of Environmental Sciences \\
\hline Bruce Kahn & University of Wisconsin, Madison, Department of Rural Sociology \\
\hline Wendy Marussich & Arizona State University, Department of Biology \\
\hline Maya McCoy & Michigan State University, Department of Sociology \\
\hline Rachel Michaels & University of Virgina, Department of Biogeochemistry \\
\hline Sonia Ortega & National Science Foundation, Division of Education \\
\hline Kristen Parris & $\begin{array}{l}\text { Royal Botanic Gardens Melbourne, Australian Research Centre for Urban } \\
\text { Ecology }\end{array}$ \\
\hline Garry Peterson & University of Wisconsin, Madison, Center for Limnology \\
\hline Jeffrey Pollock & University of Alabama, Department of Biological Sciences \\
\hline Maria Powell & University of Wisconsin, Madison, Department of Rural Sociology \\
\hline Gustavo Rubio & Florida International University, Department of Biology \\
\hline Karen Schaepe & University of Wisconsin, Madison, Department of Rural Sociology \\
\hline Kelle Stanforth & University of Dayton, Ohio, Department of Environmental Engineering \\
\hline
\end{tabular}



Eric Thobaben
Michigan State University, Department of Zoology
Ben Vail
University of Wisconsin, Madison, Department of Rural Sociology
Elly Vandegrift
Oregon State University, Department of Forest Science
Matthew Warren
University of Puerto Rico, Department of Biology
Theodore Willis
University of Wisconsin, Madison, Center for Limnology
Mitch Pavao-Zuckerman
University of Georgia, Institute of Ecology

\section{LITERATURE CITED}

Bradshaw, G. A., and M. Bekoff. 2001. Ecology and social responsibility: the re-embodiment of science. Trends in Ecology and Evolution 16:460-465.

Daily, G. C., and P. R. Ehrlich. 1999. Managing earth's ecosystems: an interdisciplinary challenge. Ecosystems 2:277-280.

Golde, C. M., and H. A. Gallagher. 1999. The challenges of conducting interdisciplinary research in traditional doctoral programs. Ecosystems 2:281-285.

Gunderson, L. H., C. S. Holling, and S. S. Light. 1995. Barriers broken and bridges built: a synthesis. Pages 489532 in L. H. Gunderson, C. S. Holling, and S. S. Light, editors. Barriers and bridges to the renewal of ecosystems and institutions. Columbia University Press, New York, New York, USA.

Jackson, L. J., A. S. Trebitz, and K. L. Cottingham. 2000. An introduction to the practice of ecological modeling. BioScience 50:694-706.

Lee, K. N. 1993. Compass and gyroscope: integrating science and politics for the environment. Island Press, Washington, D.C., USA.

Levins, R. 1966. The strategy of model building in population biology. American Scientist 54:421-431.

Naiman, R. J. 1999. A perspective on interdisciplinary science. Ecosystems 2:292-295.

Odum, H. T. 1983. Systems ecology: an Introduction. John Wiley, New York, New York, USA.

Pavao-Zuckerman, M. A. 2000. The conceptual utility of models in human ecology. Journal of Ecological Anthropology 4:37-56.

Pickett, S. T. A., W. R. Burch Jr., and J. M. Grove. 1999. Interdisciplinary research: maintaining the constructive impulse in a culture of criticism. Ecosystems 2:302-307.

Redman, C. L. 1999. Human dimensions of ecosystem studies. Ecosystems 2:296-298.

Scoones, I. 1999. New ecology and the social sciences: what prospects for a fruitful engagement? Annual Review of Anthropology 28:479-507.

Stepp, J. R. 1999. Prospectus for information ecology. Georgia Journal of Ecological Anthropology 3: 39-73.

Taylor, P. 2000. Socio-ecological webs and sites of sociality: Levins' strategy of model building revisited. Biology and Philosophy 15:197-210.

Turner, M. G., and S. R. Carpenter. 1999. Tips and traps in interdisciplinary research. Ecosystems 2:275-276.

Turner, M. G., R. H. Gardner, and R. V. O'Neill. 2001. Landscape ecology in theory and practice: pattern and process. Springer, New York, New York, USA. 